\title{
Pharmacokinetics and Safety of Esketamine in Chinese Patients Undergoing Painless Gastroscopy in Comparison with Ketamine: A Randomized, Open-Label Clinical Study
}

This article was published in the following Dove Press journal:

Drug Design, Development and Therapy

\author{
Jing Wang $\mathbb{D}^{1,2, *}$ \\ Jie Huang ${ }^{1,3, *}$ \\ Shuang Yang ${ }^{1,3}$ \\ Chang Cui ${ }^{1,3}$ \\ Ling $\mathrm{Ye}^{1,3}$ \\ Sai-ying Wang ${ }^{4}$ \\ Guo-ping Yang $\mathbb{D}^{1,3}$ \\ Qi Pei ${ }^{1,2}$
}

'Center for Clinical Pharmacology, The Third Xiangya Hospital, Central South University, Changsha, Hunan 410013, People's Republic of China; ${ }^{2}$ Department of Pharmacy, The Third Xiangya Hospital, Central South University, Changsha, Hunan 4I0013, People's Republic of China; ${ }^{3}$ Clinical Trails Center, The Third Xiangya Hospital, Central South University, Changsha, Hunan 410013, People's Republic of China; ${ }^{4}$ Department of Anesthesiology, The Third Xiangya Hospital, Central South University, Changsha, Hunan 4I00I3, People's Republic of China

*These authors contributed equally to this work

\begin{abstract}
Purpose: To assess the pharmacokinetics and safety of pure S-ketamine (esketamine) in Chinese patients undergoing painless gastroscopy and evaluate the potential advantage of esketamine in clinical treatment compared with racemate ketamine hydrochloride injection. Patients and methods: A randomized, open-label, parallel-controlled, Phase I study was performed with 32 patients undergoing painless gastroscopy. Patients received a single dose of esketamine $(0.5 \mathrm{mg} / \mathrm{kg})$ or racemic ketamine $(1 \mathrm{mg} / \mathrm{kg}$, esketamine:R-ketamine $=1: 1)$, injected in $10 \mathrm{~s}$. Blood samples were collected for pharmacokinetic analysis. The concentrations of esketamine, R-ketamine, S-norketamine, and R-norketamine were measured with a validated liquid chromatography with tandem mass spectrometry (LC-MS/MS) method.

Results: After administering a single dose of esketamine and racemate ketamine, the pharmacokinetics parameters of esketamine and S-norketamine are both similar in treatment groups. The clearance of esketamine in two groups was $18.1 \pm 3.2$ and $18.4 \pm 3.4 \mathrm{~mL} / \mathrm{min} \bullet \mathrm{kg}$, respectively. However, in the ketamine group, esketamine has a larger clearance than R-ketamine $(18.4 \pm 3.4 \mathrm{~mL} / \mathrm{min} \cdot \mathrm{kg}$ vs $15.8 \pm 3.1 \mathrm{~mL} / \mathrm{min} \cdot \mathrm{kg}, P<0.001)$. Further analysis showed that gender did not affect the pharmacokinetics of esketamine and racemate ketamine. Regarding the safety of esketamine and racemate ketamine, no serious adverse events were observed during treatment, and the incidences of adverse events were $75.0 \%$ (esketamine) and $87.5 \%$ (racemate ketamine). The main adverse reactions were dizziness, agitation, nausea, vomiting, headache, and fatigue. However, compared with racemic ketamine, esketamine offers a shorter recovery time $(9$ mins vs. 13 mins, $\mathrm{P}<0.05)$ and orientation recovery time (11.5 mins vs. 17 mins, $\mathrm{P}<0.05)$ after short anesthesia.

Conclusion: Esketamine administration as a single dose of $0.5 \mathrm{mg} / \mathrm{kg}$ was generally safe and tolerated in patients undergoing painless gastroscopy. In terms of anesthesia, a relatively small dose of esketamine can be used instead of racemate ketamine for routine treatment without consideration of gender differences.
\end{abstract}

Keywords: pharmacokinetics, esketamine, racemate ketamine, anesthesia, Chinese patients

\section{Introduction}

Ketamine is an antagonist of the N-methyl-d-aspartate receptor which has been used as an anesthetic analgesic for clinical treatment since the 1960s. ${ }^{1}$ It derived from phencyclidine (PCP) and is designed to alleviate the serious psychosis/psychotic side effects and potential abuse of maternal drugs. ${ }^{2}$ In recent years, ketamine has been found to have potential therapeutic uses in pain management, neurology, and
Correspondence: Guo-ping Yang; Qi Pei South University, Yinpenling Street, Yuelu District, Changsha, Hunan 410013,

People's Republic of China

Tel +86 I3। 704 I 9804

Fax +86 731 886I 8326

Email ygp9880@I26.com;

peiqil028@I26.com 
psychiatry. ${ }^{3-6}$ Low-dose intravenous ketamine can reduce perioperative opioid consumption and can provide chronic postsurgical pain relief for patients. ${ }^{7,8}$ High dose ketamine produces anesthetic and analgesic effects. ${ }^{9}$

Ketamine is a racemic mixture containing two optical isomers, $\mathrm{S}(+)$-ketamine (Esketamine) and R(-)-ketamine. ${ }^{10}$ Esketamine, a right-handed split of ketamine, entered the German market in 1997 and then was listed in several European countries. Its anesthetic effect is twice as potent as a racemic mixture, and its potency is approximately three times higher than (R)-ketamine. ${ }^{11-14}$ Because of the dosedependent side effects of ketamine, low-dose esketamine can reduce the incidence of anesthetic side reactions. ${ }^{15,16}$ At the equivalent dose of analgesia in healthy volunteers, esketamine has a lower incidence of psychotropic side effects than racemic ketamine, resulting in less impairment in concentration capacity and primary memory and fast recovery. ${ }^{17,18}$

At present, several studies have reported the pharmacokinetic and pharmacodynamic characteristics of ketamine and esketamine, but the results are not consistent. Geisslinger conducted a study on the stereoselective pharmacokinetics and pharmacodynamics of ketamine in surgical patients after intravenous injection of esketamine $(1 \mathrm{mg} / \mathrm{kg})$ or racemic ketamine $(2 \mathrm{mg} / \mathrm{kg}) .{ }^{19}$ It was found that esketamine was not converted to R(-)-ketamine, and the clearance of esketamine in the racemate ketamine was larger than esketamine, whereas Ihmsen performed a study of continuous pumping of esketamine and racemic ketamine in healthy volunteers, in which the clearance of esketamine in the racemate ketamine was smaller than that of esketamine alone. ${ }^{20}$

Esketamine has not been listed in China, and the pharmacokinetics and pharmacodynamics of esketamine in the Chinese require further study. Recently, Hengrui Medicine Co., Ltd. completed the preclinical study of esketamine and obtained the clinical research approval from SFDA. This study intended to use racemate ketamine hydrochloride as a reference drug to explore and compare the pharmacokinetics, efficacy, and safety of esketamine and racemate ketamine for the first time in Chinese patients and to provide information for the clinical treatment of esketamine.

\section{Materials and Methods}

\section{Participants}

A total of 32 volunteers who underwent conventional gastroscopy were included in the study (16 males and 16 females). None of them had general anesthesia contraindications. Patients who are allergic to ketamine hydrochloride, lidocaine, esketamine, propofol, opioids, tropisetron, and neostigmine, and have intolerance to belladonna alkaloids were excluded. All the volunteers provided written informed consent. They were randomized to receive esketamine $(0.5 \mathrm{mg} / \mathrm{kg})$ or racemate ketamine $(1 \mathrm{mg} / \mathrm{kg})$. In the esketamine group, volunteers were aged 23 to 44 years old, with BMIs of $19.02-25.78 \mathrm{~kg} / \mathrm{m}^{2}$. In the ketamine group, volunteers were aged 27 to 58 years old, and the BMI was $19.48-28.93 \mathrm{~kg} / \mathrm{m}^{2}$. All volunteers had ASA grades of I-II. Thirty-two volunteers completed the study, and no volunteers withdrew from the study. Table 1 summarizes the baseline demographic information.

\section{Study Design}

This was a randomized,open-label, parallel-control, singlecenter study based on a flowchart (Figure 1). The aim of this study was to evaluate the pharmacokinetics and safety profile of esketamine and racemate ketamine in patients and compare the pharmacokinetics and safety to provide a reference for clinical use. The study was approved by the Medical Ethics Committee of the Third Xiangya Hospital of Central South University. It was conducted in accordance with the principles of the Declaration of Helsinki, Good Clinical Practice Guidelines, and the Guideline for Good Clinical Principles recommended by the SFDA. This study was registered at Chinese Clinical Trial Registry (http:// www.chictr.org, number: ChiCTR-IIR-17013178). ${ }^{21}$

Table I Demographic Variables of Volunteers Who Underwent Painless Gastroscopy

\begin{tabular}{|l|l|l|}
\hline Variables & $\begin{array}{l}\text { Esketamine } \\
\text { Group }\end{array}$ & $\begin{array}{l}\text { Racemic Ketamine } \\
\text { Group }\end{array}$ \\
\hline Total number & 16 & 16 \\
\hline $\begin{array}{c}\text { Sex (\%) } \\
\text { Male } \\
\text { Female }\end{array}$ & $\begin{array}{l}8(50.00 \%) \\
8(50.00 \%)\end{array}$ & $\begin{array}{l}8(50.00 \%) \\
8(50.00 \%)\end{array}$ \\
\hline Age, years & $32.00 \pm 6.19$ & $40.00 \pm 8.91$ \\
\hline Height, m & $1.65 \pm 0.09$ & $1.65 \pm 0.11$ \\
\hline Weight, kg & $59.55 \pm 9.73$ & $63.66 \pm 13.86$ \\
\hline BMI, kg/m ${ }^{2}$ & $21.63 \pm 1.96$ & $23.05 \pm 2.69$ \\
\hline ASA grade & $1-I I$ & $1-I I$ \\
\hline $\begin{array}{l}\text { Modified Mallampati } \\
\text { Score }\end{array}$ & 1 & $1-I I$ \\
\hline
\end{tabular}

Notes: Data are the mean \pm SD, except sex (male/female), which is the \%. Abbreviations: BMI, body mass index; SD, standard deviation. 


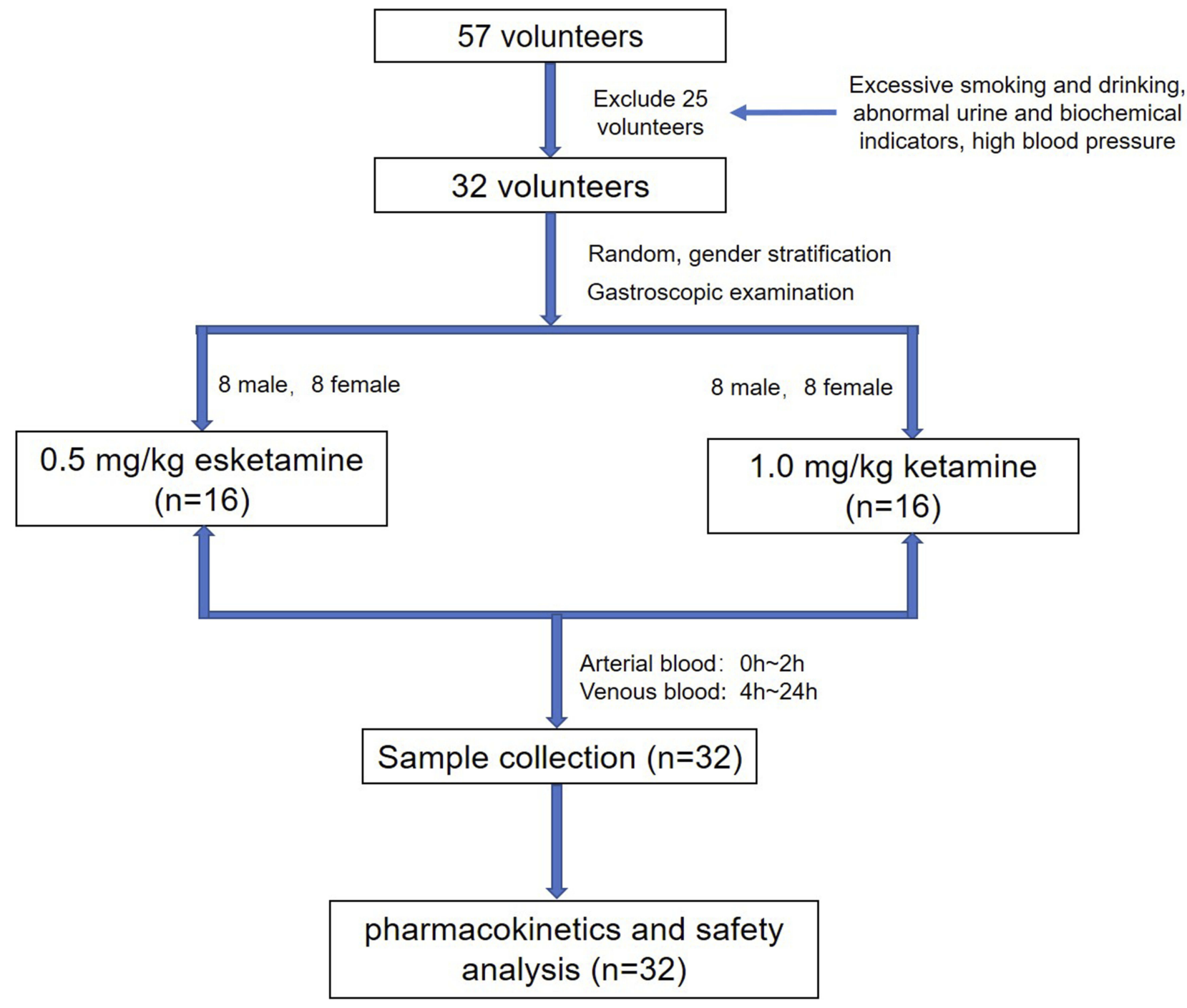

Figure I Flowchart of the study design. Blank indicating that randomized, open-label, parallel-control trail until Pharmacokinetics and safety analysis.

Volunteers were asked for information about previous medical history and history of drug use. Then, patients underwent physical and laboratory tests, baseline vital signs, height, weight were recorded, and body mass index was calculated. Before the examination, $2 \mathrm{~mL}$ of $2 \%$ lidocaine cement was used for local anesthesia in the throat, in addition to subcutaneous injection of $2 \%$ lidocaine $0.2-0.5 \mathrm{~mL}$. When painless gastroscopic anesthesia was performed, according to the weight of the patients, the appropriate volume of racemate ketamine hydrochloride solution $(10 \mathrm{mg} / \mathrm{mL})$ or esketamine hydrochloride solution $(5 \mathrm{mg} / \mathrm{mL}$ ) was intravenously administered to the subject (injection within $10 \mathrm{~s}$ ). Immediate intravenous injection of propofol $0.6 \mathrm{mg} / \mathrm{kg}$ was administered and an endoscopic examination was started when the eyelash reflex disappeared, and no obvious limb activity occurred.
Simultaneously, propofol was continuously pumped at a rate of $0.25 \mathrm{mg} / \mathrm{kg} / \mathrm{hr}$ for $15 \mathrm{mins}$. If there was obvious body motion or swallowing reflex, $0.5 \mathrm{mg} / \mathrm{kg}$ propofol was added. In this study, it takes approximately $19 \pm 6$ mins to do a gastroscopic examination, and only the oral dilator was used to dilate the oral cavity, no additional muscle relaxants or endotracheal intubation was used.

\section{Blood Collection and Bioanalysis}

Arterial blood samples ( $3 \mathrm{~mL}$ each) were collected before dose administration $(0 \mathrm{hr})$, immediately after the end of injection, 1 min, 2 mins, 4 mins, 6 mins, 10 mins, 20 mins, $30 \mathrm{mins}, 1 \mathrm{hr}, 1.5 \mathrm{hrs}$, and $2 \mathrm{hrs}$ after dosing. Venous blood samples were collected at $4 \mathrm{hrs}, 6 \mathrm{hrs}, 8 \mathrm{hrs}, 12 \mathrm{hrs}$, and $24 \mathrm{hrs}$ after dosing. Plasma samples were frozen at $20^{\circ} \mathrm{C}$ before analysis. 
Pharmacokinetic measurements of esketamine, R-ketamine, R-norketamine, and S-norketamine in plasma were performed using liquid chromatography with tandem mass spectrometry (LC-MS/MS) after liquid-liquid extraction. Gradient elution was performed on a CHIRALPAK ${ }^{\circledR}$ AGP $5 \mu \mathrm{m}, 150 \times 4.0 \mathrm{~mm}$ column with trimethoprim as an internal standard. Using positive ion mode, MRM, the ion pairs of esketamine, R-ketamine, R-norketamine and S-norketamine, and internal standard are $238.800 \rightarrow 125.100,238.801 \rightarrow 125.101,224.001 \rightarrow 163.001$, $224.000 \rightarrow 163.000$ and $291.600 \rightarrow 230.100$, respectively. The calibrated range of the method was 2.50 to $1250 \mathrm{ng} /$ $\mathrm{mL}$ for all analytes. The intra- and inter-day precisions $(\mathrm{CV}$, $\%$ ) were $<15 \%$, and the accuracies ( $\%$ ) were within the range of $85.0-115.0 \%$.

\section{Pharmacokinetic Analysis}

Pharmacokinetic analysis was made from both arterial blood and venous blood and performed with a noncompartmental method using the Pheonix WinNonlin 7.0 (Pharsight Corporation, CA, USA). Actual blood sampling time of each patient was used for analysis. Maximum observed drug concentrations $\left(\mathrm{C}_{\max }\right)$ and time of maximum observed drug concentration $\left(\mathrm{T}_{\max }\right)$ were obtained directly from the plasma concentration-time curves of esketamine and racemate ketamine. The area under the plasma concentration-time curve from time 0 to the last measurement $\left(\mathrm{AUC}_{0-\mathrm{t}}\right)$ was calculated using the linear trapezoidal method for ascending concentrations and the $\log$ trapezoidal method for descending concentrations. The $\mathrm{AUC}_{0-} \propto$ was calculated as $\mathrm{AUC}_{0-\mathrm{t}}+\mathrm{C}_{\mathrm{t}} / \lambda_{\mathrm{z}}$, where $\mathrm{C}_{\mathrm{t}}$ is the last measured concentration, and $\lambda_{\mathrm{z}}$ is the elimination rate constant calculated using linear regression of the log-linear portion of the plasma concentration-time curve. Clearance (CL) was estimated as dose divided by $\mathrm{AUC}_{0-\square}$, and the volume of distribution (V) was determined by dividing the apparent CL by $\lambda_{\mathrm{z}}$.

\section{Safety Assessment}

Safety was assessed according to interviews and adverse event (AE) monitoring. All adverse events that occurred during the clinical study were required to be reported, including abnormalities in clinical symptoms, vital signs, and laboratory tests, and the clinical significance was determined by the monitoring physician. The occurrence, severity, and frequency of $\mathrm{AE}$ and/or adverse drug reactions were compared between two treatment groups. If clinical abnormalities were present, further follow-ups were required.

\section{Anesthesia Recovery Index}

The anesthesia recovery time and orientation recovery time were recorded. Patient's recovery time was defined as the time between the administration of the drug and patient's modified OAA/S (Observer's Assessment of Alertness/Sedation Scale) score of 5. The recovery orientation was assessed by the "orientation test". Patients were asked for 10 questions (1 score per question, total of 10 scores); the number of correctly answered questions was counted for each patient. The time from the administration of the drug to the patient's orientation score of 10 was determined as the orientation recovery time. Sedation scores were used to assess the degree of sedation at 15 mins, 30 mins, and 60 mins after palinesthesia.

\section{Statistical Analyses}

This study mainly focuses on PK properties, anesthetic outcomes are secondary findings, the sample size calculations are performed based on clinical pharmacokinetics study guidance. According to the Guidelines for the Study of Clinical Pharmacokinetics of Chemical Drugs recommended by the SFDA, ${ }^{22}$ pharmacokinetic studies require 8-12 volunteers per group. And Guidance for Industry of Statistical Approaches to Establishing Bioequivalence by FDA suggests that a minimum number of 12 evaluable subjects should be included in any $\mathrm{BE}$ study. $^{23}$ Given the $20 \%$ drop-out rate, 16 patients were enrolled in the esketamine group and the ketamine group, respectively.

Statistical analysis was conducted using SAS software version 9.4 (SAS Institute Inc., Cary, NC, USA). Student's $t$-test and paired $t$-test were performed on the logarithmically transformed pharmacokinetic parameters (except Tmax) to assess the statistical significance of the two groups. The differences of Tmax, recovery time, and orientation recovery time were further confirmed by the Wilcoxon Mann-Whitney rank-sum test. Sedation score was analyzed using a Cochran Mantel-Haenszel (CMH) chi-square test. $\mathrm{P}<0.05$ was considered to be significant.

\section{Results}

\section{Pharmacokinetics}

The mean plasma concentration versus time profiles for esketamine and R-ketamine after administering a single dose of esketamine $(0.5 \mathrm{mg} / \mathrm{kg}$, test group) and racemate ketamine ( $1 \mathrm{mg} / \mathrm{kg}$, esketamine:R-ketamine $=1: 1$, reference group) are shown in Figure 2. The pharmacokinetic 

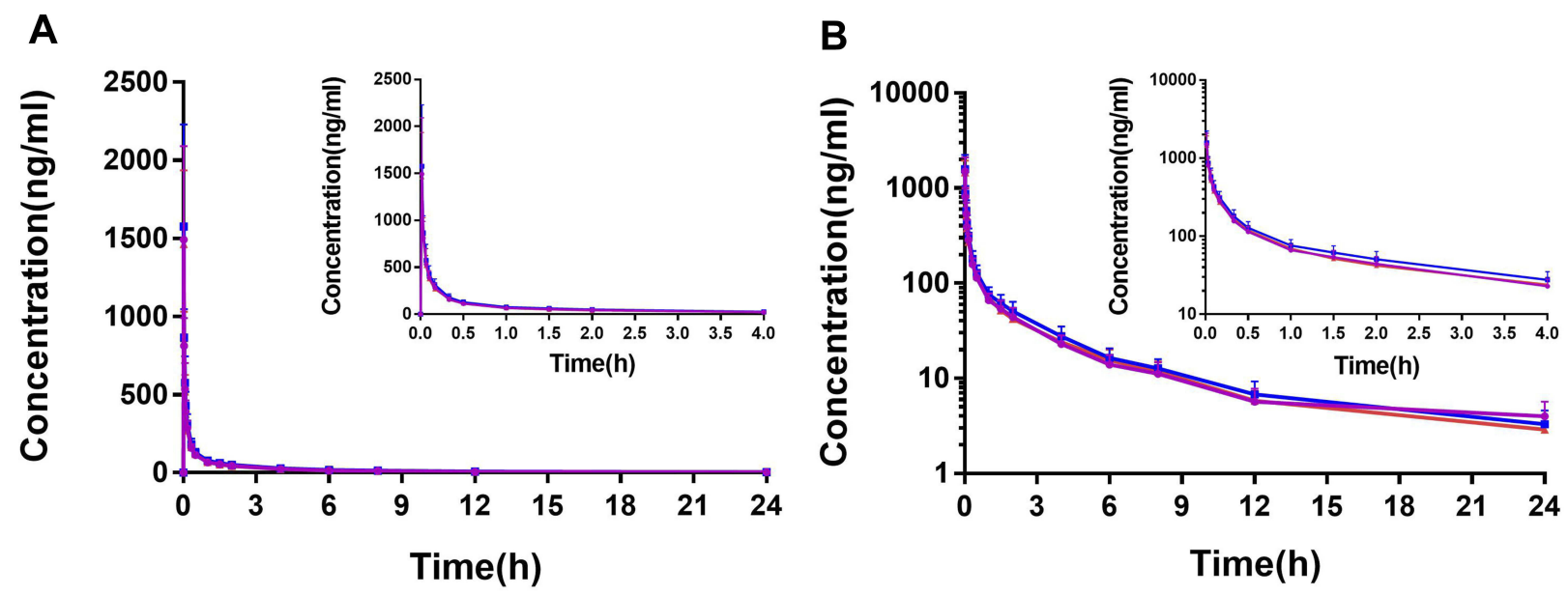

$\rightarrow$ Esketamine(ketamine group) $\rightarrow$ R-ketamine(ketamine group) $\rightarrow$ Esketamine(esketamine group)

Figure 2 Mean (SD) plasma concentration-time curves of esketamine $(0.5 \mathrm{mg} / \mathrm{kg})$ and ketamine $(\mathrm{I} \mathrm{mg} / \mathrm{kg})$ in ordinary coordinates and semi-log coordinates. (A) Ordinary coordinates curve for esketamine in two groups, and R-ketamine in the racemate ketamine group. (B) Semi-log coordinates curves for esketamine in two groups, and R-ketamine in the racemate ketamine group.

A

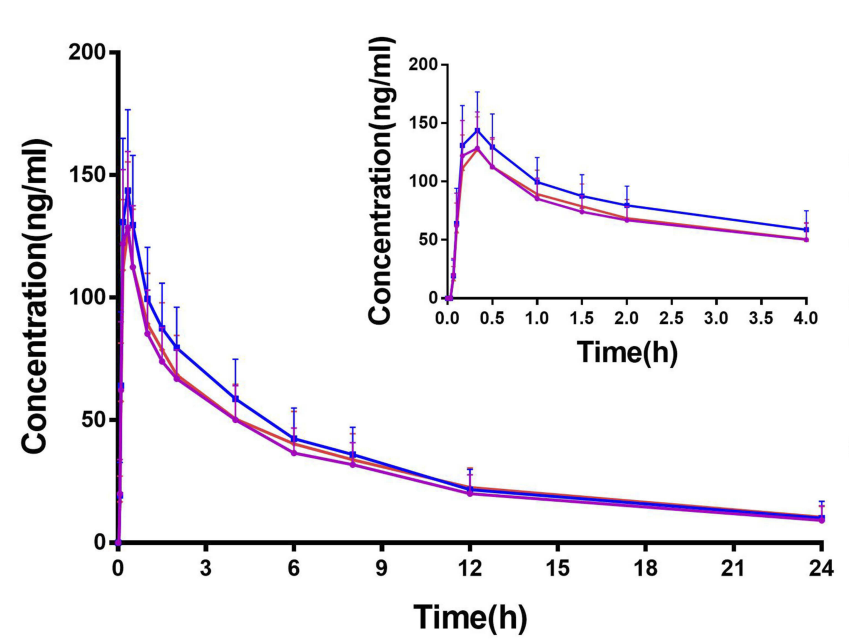

B

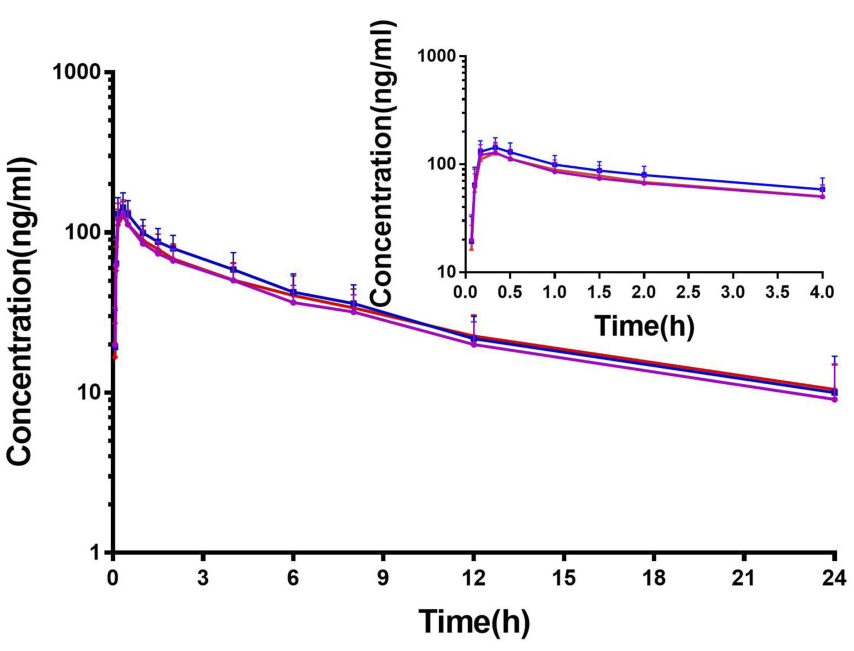

$\rightarrow$ S-norketamine(ketamine group) $\rightarrow$ R-norketamine(ketamine group) - S-norketamine(esketamine group)

Figure 3 Mean (SD) plasma concentration-time curves of S-norketamine and R-norketamine in ordinary coordinates and semi-log coordinates. (A) Ordinary coordinate curves for S-norketamine in two groups and R-norketamine in the racemate ketamine group. (B) Semilog coordinates curves for S-norketamine in two groups and R-norketamine in the racemate ketamine group.

parameters and statistics of esketamine and R-ketamine are shown in Table 2. The pharmacokinetic parameters of esketamine in pure isomers were close to those obtained in the racemate. After administration of racemate ketamine, the comparison of variables revealed a significant difference of esketamine and R-ketamine within groups (except Tmax and Vz)

For the main metabolite S-norketamine, the pharmacokinetic variables of S-norketamine following administration of the single esketamine were similar to the administration of the racemate ketamine. The main pharmacokinetic parameters of the metabolites S-norketamine and R-norketamine are shown in Table 2 and mean plasma concentration-time curves of S-norketamine and R-norketamine are shown in Figure 3.

This study also compared sex differences in the kinetic profile of esketamine and its major metabolite. As shown in Table 3, gender had no significant effect 
Table 2 The Pharmacokinetic Parameters of Esketamine, R-Ketamine, S-Norketamine, and R-Norketamine in the Esketamine Group and the Ketamine Group

\begin{tabular}{|c|c|c|c|c|}
\hline \multicolumn{2}{|l|}{ Parameters } & \multirow[b]{2}{*}{$\begin{array}{l}\text { Esketamine Group }(\mathbf{N}=16) \\
1.17(0.28-1.25) \\
2277.60 \pm 2697.60 \\
441.90 \pm 85.50 \\
475.20 \pm 86.50 \\
18.10 \pm 3.20 \\
287.50 \pm 110.20 \\
7390.80 \pm 2703.70\end{array}$} & \multirow[b]{2}{*}{$\begin{array}{l}\text { Racemic Ketamine Group }(\mathbf{N}=\mid \mathbf{6}) \\
1.15(0.23-1.28) \\
1976.80 \pm|5| 8.70 \\
435.70 \pm 89.60 \\
469.00 \pm 99.50 \\
18.40 \pm 3.40 \\
283.20 \pm \mid 17.80 \\
7285.90 \pm 254 \mid .90\end{array}$} & \multirow[b]{2}{*}{$\begin{array}{l}\mathbf{P} \\
0.225^{\mathrm{a}} \\
0.86 \mathrm{I}^{\mathrm{b}} \\
0.828^{\mathrm{b}} \\
0.803^{\mathrm{b}} \\
0.804^{\mathrm{b}} \\
0.864^{\mathrm{b}} \\
0.964^{\mathrm{b}}\end{array}$} \\
\hline Esketamine & $\begin{array}{l}\operatorname{Tmax}(\mathrm{min}) \\
\mathrm{Cmax}(\mathrm{ng} / \mathrm{mL}) \\
\mathrm{AUC}_{0-\mathrm{t}}(\mathrm{h} \cdot \mathrm{ng} / \mathrm{mL}) \\
\mathrm{AUC}_{0-\infty}(\mathrm{h} \cdot \mathrm{ng} / \mathrm{mL}) \\
\mathrm{CL}(\mathrm{mL} / \mathrm{min} \mathrm{kg}) \\
\mathrm{t}_{\mathrm{I} / 2}(\mathrm{~min}) \\
V(\mathrm{~mL} / \mathrm{kg})\end{array}$ & & & \\
\hline R-ketamine & $\begin{array}{l}\mathrm{T}_{\max }(\mathrm{min}) \\
\mathrm{C}_{\max }(\mathrm{ng} / \mathrm{mL}) \\
\mathrm{AUC}_{0-\mathrm{t}}(\mathrm{h} \cdot \mathrm{ng} / \mathrm{mL}) \\
\mathrm{AUC}_{0-\infty}(\mathrm{h} \cdot \mathrm{ng} / \mathrm{mL}) \\
\mathrm{CL}(\mathrm{mL} / \mathrm{min} \mathrm{kg}) \\
\mathrm{t}_{\mathrm{I} / 2}(\mathrm{~min}) \\
V(\mathrm{~mL} / \mathrm{kg})\end{array}$ & $\begin{array}{l}- \\
- \\
- \\
- \\
- \\
- \\
-\end{array}$ & $\begin{array}{l}1.15(0.23-1.28) \\
2064.40 \pm 1573.90 \\
510.50 \pm 113.10 \\
547.30 \pm 121.60 \\
15.80 \pm 3.10 \\
343.40 \pm \mid 12.70 \\
76 \mid 4.80 \pm 2150.00\end{array}$ & $\begin{array}{l}\mathrm{I} .000^{\mathrm{c}} \\
<0.00 I^{* * \mathrm{~d}} \\
<0.00 I^{* * \mathrm{~d}} \\
<0.00 I^{* *} \mathrm{~d} \\
<0.00 \text { I }^{*} \mathrm{~d} \\
0.003^{* *} \mathrm{~d} \\
0.265^{\mathrm{b}}\end{array}$ \\
\hline S-norketamine & $\begin{array}{l}\mathrm{T}_{\max }(\mathrm{min}) \\
\mathrm{C}_{\max }(\mathrm{ng} / \mathrm{mL}) \\
A \cup C_{0-\mathrm{t}}(\mathrm{h} \cdot \mathrm{ng} / \mathrm{mL}) \\
A \cup C_{0-\infty}(\mathrm{h} \cdot \mathrm{ng} / \mathrm{mL}) \\
\mathrm{CL}(\mathrm{mL} / \mathrm{min} \mathrm{kg}) \\
\mathrm{t}_{\mathrm{l} / 2}(\mathrm{~min}) \\
V(\mathrm{~mL} / \mathrm{kg})\end{array}$ & $\begin{array}{l}20.17(10.15-20.22) \\
129.70 \pm 28.9 \\
764.60 \pm 222.00 \\
871.00 \pm 262.30 \\
10.10 \pm 3.30 \\
519.00 \pm 117.00 \\
7593.70 \pm 2399.40\end{array}$ & $\begin{array}{l}10.19(10.12-20.20) \\
136.00 \pm 29.10 \\
723.80 \pm 1860.80 \\
782.80 \pm 158.20 \\
10.60 \pm 3.00 \\
475.10 \pm 65.90 \\
7806.50 \pm 2173.40\end{array}$ & $\begin{array}{l}0.065^{a} \\
0.544^{b} \\
0.662^{b} \\
0.622^{b} \\
0.624^{b} \\
0.826^{b} \\
0.736^{b}\end{array}$ \\
\hline R-norketamine & $\begin{array}{l}T_{\max }{ }^{a}(\min ) \\
C_{\max }(\mathrm{ng} / \mathrm{mL}) \\
A \cup C_{0-\mathrm{t}}(\mathrm{h} \cdot \mathrm{ng} / \mathrm{mL}) \\
A \cup C_{0-\infty}(\mathrm{h} \cdot \mathrm{ng} / \mathrm{mL}) \\
C L(\mathrm{~mL} / \mathrm{min} \cdot \mathrm{kg}) \\
\mathrm{t}_{\mathrm{I} / 2}(\mathrm{~min}) \\
V(\mathrm{~mL} / \mathrm{kg})\end{array}$ & $\begin{array}{l}- \\
- \\
- \\
- \\
- \\
- \\
-\end{array}$ & $\begin{array}{l}20.13(10.15-30.0) \\
149.40 \pm 32.60 \\
822.40 \pm 216.10 \\
882.40 \pm 217.00 \\
9.50 \pm 2.80 \\
453.80 \pm 64.40 \\
6640.90 \pm 1794.70\end{array}$ & $\begin{array}{l}- \\
- \\
- \\
- \\
- \\
- \\
-\end{array}$ \\
\hline
\end{tabular}

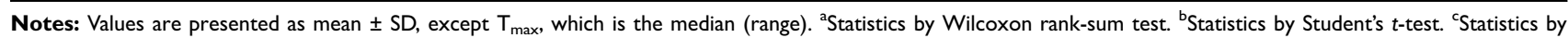
Wilcoxon signed-rank-sum test. ${ }^{\mathrm{d}}$ Statistics by paired $t$-test. $* * \mathrm{P}<0.0 \mathrm{I}$.

Abbreviations: $C_{\max }$, maximum plasma concentration; $T_{\max }$, time to reach $C_{\max }$; $\mathrm{AUC}_{0-\infty}$, area under the plasma concentration-time curve from time zero to infinity; $\mathrm{AUC}_{0-\mathrm{t}}$, area under the plasma concentration-time curve from zero until last measurable concentration; $\mathrm{t}_{1 / 2}$, elimination half-life; SD, standard deviation.

on the pharmacokinetics of racemate ketamine and esketamine.

\section{Safety}

Twenty-three AEs occurred in 12 volunteers who were administered at least one dose of esketamine. The incidence of $\mathrm{AE}$ was $75.0 \%$, of which 16 were considered as related to treatment. There were 31 AEs in the ketamine group, and the $\mathrm{AE}$ incidence rate was $87.5 \%$, with 25 cases related to treatment. The main adverse reactions were dizziness, agitation, nausea, vomiting, headache, fatigue, high blood pressure, cramps, tremors, hypertonia, and cold sweat. There were no serious AEs and serious adverse reactions reported, and none of the volunteers withdrew from the study due to AEs. The distribution and incidence of AEs related to the study drugs in each group are shown in Table 4.

\section{Anesthesia Recovery Index}

The results are shown in Table 5. Under the lower maintenance dose regimen of propofol $(0.25 \mathrm{mg} / \mathrm{kg} / \mathrm{hr}$, continuous pumping for 15 mins) in this trial, 9 patients woke up approximately $4.9 \pm 2.4$ mins before stopping propofol dosing, and 7 patients woke up approximately 3.0 \pm 3.5 mins after stopping propofol dosing in ketamine group, and all the patients woke up $7.0 \pm 3.1 \mathrm{mins}$ before stopping esketamine dosing. The sedation score in the esketamine and ketamine groups was similar at each time point after 
Table 3 The Pharmacokinetic Parameters of Esketamine and S-Norketamine in Different Genders (Esketamine Group)

\begin{tabular}{|c|c|c|c|c|}
\hline \multicolumn{2}{|l|}{ Parameters } & \multirow[b]{2}{*}{$\begin{array}{l}\text { Male }(\mathbf{N}=\mathbf{8}) \\
1.18(0.32-1.25) \\
2885.90 \pm 3726.90 \\
480.90 \pm 86.60 \\
512.60 \pm 91.80 \\
16.70 \pm 3.10 \\
243.00 \pm 77.30\end{array}$} & \multirow[b]{2}{*}{$\begin{array}{l}\text { Female }(\mathbf{N}=8) \\
1.15(0.28-1.20) \\
1669.40 \pm 926.10 \\
402.80 \pm 68.40 \\
437.80 \pm 66.30 \\
19.40 \pm 2.70 \\
332.00 \pm 124.60\end{array}$} & \multirow[b]{2}{*}{$\begin{array}{l}\mathbf{P} \\
0.166^{\mathrm{a}} \\
0.465^{\mathrm{b}} \\
0.062^{\mathrm{b}} \\
0.086^{\mathrm{b}} \\
0.088^{\mathrm{b}} \\
0.125^{\mathrm{b}}\end{array}$} \\
\hline Esketamine & $\begin{array}{l}T_{\max }(\mathrm{min}) \\
C_{\max }(\mathrm{ng} / \mathrm{mL}) \\
A \cup C_{0-\mathrm{t}}(\mathrm{h} \cdot \mathrm{ng} / \mathrm{mL}) \\
A \cup C_{0-\infty}(\mathrm{h} \cdot \mathrm{ng} / \mathrm{mL}) \\
C L(\mathrm{~mL} / \mathrm{min} / \mathrm{kg}) \\
\mathrm{t}_{1 / 2}(\mathrm{~min})\end{array}$ & & & \\
\hline S-norketamine & $\begin{array}{l}T_{\max }(\min ) \\
C_{\max }(\mathrm{ng} / \mathrm{mL}) \\
A \cup C_{0-\mathrm{t}}(\mathrm{h} \cdot \mathrm{ng} / \mathrm{mL}) \\
A \cup C_{0-\infty}(\mathrm{h} \cdot \mathrm{ng} / \mathrm{mL}) \\
C L(\mathrm{~mL} / \mathrm{min} / \mathrm{kg}) \\
\mathrm{t}_{1 / 2}(\mathrm{~min})\end{array}$ & $\begin{array}{l}20.18(10.15-20.22) \\
134.50 \pm 33.60 \\
862.90 \pm 235.60 \\
1003.00 \pm 295.80 \\
9.20 \pm 3.90 \\
477.80 \pm 115.60\end{array}$ & $\begin{array}{l}20.16(10.15-20.20) \\
124.90 \pm 24.80 \\
666.40 \pm 167.40 \\
720.10 \pm 92.70 \\
11.00 \pm 2.50 \\
566.00 \pm 107.20\end{array}$ & $\begin{array}{l}0.488^{\mathrm{a}} \\
0.583^{\mathrm{b}} \\
0.118^{\mathrm{b}} \\
0.228^{\mathrm{b}} \\
0.227^{\mathrm{b}} \\
0.08 \mathrm{I}^{\mathrm{b}}\end{array}$ \\
\hline
\end{tabular}

Notes: Values are presented as mean $\pm \mathrm{SD}$, except $T_{\max }$, which is the median (range). ${ }^{\text {a }}$ Statistics by Wilcoxon rank-sum test. ${ }^{\text {b }}$ Statistics by Student's $t$-test. Abbreviations: $C_{\max }$, maximum plasma concentration; $T_{\max }$, time to reach $C_{\max }$; $A \cup C_{0-\infty}$, area under the plasma concentration-time curve from time zero to infinity; $A \cup C_{0-t}$, area under the plasma concentration-time curve from zero until last measurable concentration; $t_{1 / 2}$, elimination half-life; SD, standard deviation.

palinesthesia $(\mathrm{P}>0.05)$. The recovery time and orientation recovery time of the two groups were significantly

Table 4 Summary of the Number and Types of Adverse Events That Related to the Drugs in Each Group

\begin{tabular}{|l|l|l|}
\hline AE Type & $\begin{array}{l}\text { Esketamine } \\
\text { (Number) }\end{array}$ & $\begin{array}{l}\text { Racemic Ketamine } \\
\text { (Number) }\end{array}$ \\
\hline Intense & 4 & $\mathrm{I}$ \\
\hline Fatigue & $\mathrm{I}$ & - \\
\hline Hypertension & $\mathrm{I}$ & 2 \\
\hline Vomiting & 3 & 3 \\
\hline Dizziness & 5 & 9 \\
\hline Delirium & 1 & 1 \\
\hline Tremor & - & 1 \\
\hline Nausea & - & 3 \\
\hline Sedation & 1 & 1 \\
\hline Cold sweat & - & 1 \\
\hline $\begin{array}{l}\text { Headache } \\
\text { Total }\end{array}$ & - & 2 \\
\hline $\begin{array}{l}\text { Muscular } \\
\text { hypertonia }\end{array}$ & - & 16 \\
\hline $\begin{array}{l}\text { Related To drug } \\
\text { Pertainly }\end{array}$ & 1 & 25 \\
\hline
\end{tabular}

Note: Values are presented as number of patients. Abbreviation: $A E$, adverse event.
Table 5 Evaluation of Anesthesia Recovery Index After Palinesthesia

\begin{tabular}{|c|c|c|c|c|}
\hline \multicolumn{2}{|l|}{ Index } & $\begin{array}{l}\text { Esketamine } \\
\text { Group }\end{array}$ & $\begin{array}{l}\text { Racemic } \\
\text { Ketamine Group }\end{array}$ & $\mathbf{P}$ \\
\hline $\begin{array}{l}\text { Sedation } \\
\text { score }\end{array}$ & $\begin{array}{l}0 \mathrm{~min} \\
15 \mathrm{~min} \\
30 \mathrm{~min} \\
60 \mathrm{~min}\end{array}$ & $\begin{array}{l}1.00(1.00-3.00) \\
2.00(1.00-3.00) \\
2.00(1.00-3.00) \\
2.00(2.00-2.00)\end{array}$ & $\begin{array}{l}1.00(1.00-1.00) \\
2.00(1.00-2.00) \\
2.00(1.00-2.00) \\
2.00(1.00-2.00)\end{array}$ & $\begin{array}{l}0.317^{\mathrm{e}} \\
0.599^{\mathrm{e}} \\
0.489^{\mathrm{e}} \\
0.317^{\mathrm{e}}\end{array}$ \\
\hline \multicolumn{2}{|c|}{ Recovery time } & $9.00(4.00-15.00)$ & $13.00(5.00-26.00)$ & $0.006 * * a$ \\
\hline \multicolumn{2}{|c|}{$\begin{array}{l}\text { Orientation } \\
\text { recovery time }\end{array}$} & $11.50(6.00-25.00)$ & $17.00(6.00-29.00)$ & $0.00 I^{* * a}$ \\
\hline
\end{tabular}

Notes: Values are presented as median (range). ${ }^{a}$ Statistics by Wilcoxon rank-sum test. ${ }^{\mathrm{e}}$ Statistics by $\mathrm{CMH}$ chi-square test. $* * \mathrm{P}<0.01$.

different, and esketamine offers a shorter recovery time (9 mins vs 13 mins, $\mathrm{P}<0.05$ ) and orientation recovery time (11.5mins vs $17 \mathrm{mins}, \mathrm{P}<0.05)$ after short anesthesia compared to racemic ketamine. The effects of propofol on the recovery time were comparable in two groups, due to the same dosage regimen for propofol in the whole study. However, the anesthesia recovery index did not show statistical differences between males and females (Table 6).

\section{Discussion}

The purpose of this study was to evaluate and compare the pharmacokinetics, efficacy, and safety of esketamine with those of racemate ketamine in Chinese patients. The pharmacokinetic parameters of esketamine and S-norketamine are both similar in the pure isomer and the racemate. The results of safety showed that a single dose of $0.5 \mathrm{mg} / \mathrm{kg}$ of esketamine and $1 \mathrm{mg} / \mathrm{kg}$ of 
Table 6 Evaluation of Anesthesia Recovery Index After Palinesthesia in Different Genders (Esketamine Group)

\begin{tabular}{|c|c|c|c|c|c|}
\hline \multicolumn{3}{|l|}{ Index } & \multirow{5}{*}{$\begin{array}{l}\text { Male }(\mathbf{N}=8) \\
1.00(1.00-3.00) \\
2.00(1.00-2.00) \\
2.00(1.00-2.00) \\
2.00(2.00-2.00)\end{array}$} & \multirow{5}{*}{$\begin{array}{l}\text { Female }(\mathbf{N}=8) \\
1.00(1.00-1.00) \\
1.50(1.00-3.00) \\
2.00(1.00-3.00) \\
2.00(2.00-2.00)\end{array}$} & \multirow{5}{*}{$\begin{array}{l}P \\
0.216^{\mathrm{e}} \\
0.197^{\mathrm{e}} \\
0.226^{\mathrm{e}} \\
1.000^{\mathrm{e}}\end{array}$} \\
\hline Esketamine & Sedation score & $0 \mathrm{~min}$ & & & \\
\hline & & $15 \mathrm{~min}$ & & & \\
\hline & & $30 \mathrm{~min}$ & & & \\
\hline & & $60 \mathrm{~min}$ & & & \\
\hline & \multicolumn{2}{|l|}{ Recovery time } & $8.5(5.00-13.00)$ & $9.50(4.00-15.00)$ & $0.874^{\mathrm{a}}$ \\
\hline & \multicolumn{2}{|c|}{ Orientation recovery time } & II.5(6.00-19.00) & $11.00(6.00-25.00)$ & $0.710^{\mathrm{a}}$ \\
\hline \multirow[t]{6}{*}{ Ketamine } & Sedation score & $0 \mathrm{~min}$ & $1.00(1.00-1.00)$ & $1.00(1.00-1.00)$ & $1.000^{\mathrm{e}}$ \\
\hline & & $15 \mathrm{~min}$ & $1.00(1.00-2.00)$ & $2.00(1.00-2.00)$ & $0.177^{\mathrm{e}}$ \\
\hline & & $30 \mathrm{~min}$ & $2.00(1.00-2.00)$ & $2.00(2.00-2.00)$ & $0.484^{e}$ \\
\hline & & $60 \mathrm{~min}$ & $2.00(1.00-2.00)$ & $2.00(2.00-2.00)$ & $0.484^{e}$ \\
\hline & \multicolumn{2}{|l|}{ Recovery time } & $11.50(5.00-26.00)$ & $14.50(8.00-17.00)$ & $0.705^{\mathrm{a}}$ \\
\hline & \multicolumn{2}{|c|}{ Orientation recovery time } & $16.00(6.00-29.00)$ & $17.50(13.00-21.00)$ & $0.605^{\mathrm{a}}$ \\
\hline
\end{tabular}

Notes: Values are presented as median (range). ${ }^{a}$ Statistics by Wilcoxon rank-sum test. ${ }^{\text {e}}$ Statistics by CMH chi-square test.

ketamine were both safe and well tolerated in Chinese patients with no serious adverse events. Also, there were no sex differences in the pharmacokinetics of esketamine and S-norketamine in the pure isomer. However, compared with racemate ketamine, esketamine had a shorter recovery time and orientation recovery time, which present potential clinical advantages.

In the current study, the pharmacokinetic parameters of esketamine and S-norketamine in the esketamine and racemate ketamine groups are both comparable. A similar phenomenon was also observed in the study of Geisslinger. ${ }^{19}$ However, Ihmsen found that esketamine had a higher clearance in the pure isomer than for the racemate. ${ }^{20}$ The modes of administration and pharmacokinetic interactions may partly account for the inconsistencies, which was also mentioned by Ihmsen. The continuous infusion for esketamine and ketamine was used in the study of Ihmsen, but the short injection was adopted in the current study and Geisslinger's study. Since the volunteers were patients, other drugs were administrated with esketamine and ketamine in our study (propofol and lidocaine) and in Geisslinger's study (midazolam). Hence, the possible pharmacokinetic interactions may induce inconsistent results. Though patients in both esketamine and ketamine groups were combined with propofol during anesthesia process, the dose regimen of propofol of two groups was identical $(0.6 \mathrm{mg} / \mathrm{kg}$ for the loading dose; $0.25 \mathrm{mg} / \mathrm{kg} / \mathrm{hr}$ for the maintenance dose). Therefore, the effect of propofol was considered to be balanced in two groups. In addition, Ihmsen also pointed out the difference between arterial and venous blood samples, arterial blood samples are more appropriate to estimate the pharmacokinetic profile, but only during the first minutes of or after administration venous concentrations tend to be smaller than the arterial concentrations. In the present study, in order to consider the convenience of clinical operation and safety issues (collection arterial blood samples are relative easier under anesthesia), arterial blood samples were collected in the first $2 \mathrm{hrs}$ in the operating room, and venous blood samples were collected afterwards (patients returned to the Phase I ward). Therefore, the type of blood samples was not a possible reason for the inconsistencies.

Marnix found that the clearance of esketamine and S-norketamine was $20 \%$ greater in women, with higher drug plasma concentrations in men. ${ }^{24}$ However, no significant difference for pharmacokinetics of esketamine and S-norketamine between genders was observed in the current study (Table 3) and anesthesia recovery index is comparable between gender (Table 6). In our study, the $\mathrm{P}$ value for gender difference for AUC of esketamine might be change (e.g., less than 0.05), if the sample size is expanded. However, the relative change of AUC between genders was less than $20 \%$, which was considered clinically irrelevant. In addition, no significant gender difference was observed in the efficacy of the esketamine (Table 6). Based on our pharmacokinetic data and anesthesia recovery index result, we consider that Chinese patients with different genders may not require dose adjustment in the administration of esketamine and ketamine.

The post-awake sedation score observed in the study showed no significant difference between the esketamine 
and racemic ketamine groups, but the recovery time and orientation recovery time were shorter in the esketamine group ( $\mathrm{P}<0.05$ ). The probable reason is that both esketamine and R-ketamine act on the N-methyl-D-aspartate receptor and then produce anesthetic and analgesic effects. ${ }^{11}$ Therefore, esketamine can better meet the requirements of outpatient gastroscopy, which could make patients wake up and return to normal faster than racemic ketamine.

The limitation of this study was the lack of evaluation of cognitive impairment after recovery, such as mood and clustered psychological effects and concentration capacity. Further studies on the relationship between pharmacokinetics and perceptual/cognitive effects of esketamine are needed.

\section{Conclusion}

This is the first study to investigate the pharmacokinetic properties (parent and metabolites and gender difference) as well as pharmacodynamic response (e.g., recovery time, sedation score) of esketamine in Chinese population. Our results regarding pharmacokinetics and pharmacodynamics parameters do not differ from previous studies conducted in population with different ethnicities. This noethnical difference finding of esketamine is important to confirm its efficacy and feasibility for routine surgical anesthesia, and we consider that Chinese patients with different genders may not require dose adjustment in the administration of esketamine and ketamine.

\section{Ethical Approval}

This study has been approved by the Medical Ethics Committee of the Third Xiangya Hospital of Central South University and has been performed according to the ethical standards laid down in the 1964 Declaration of Helsinki.

\section{Data Sharing Statement}

The raw data of this study will not be shared because of confidentiality.

\section{Informed Consent}

Informed consent was written by all individual participants included in the study.

\section{Acknowledgments}

This study was supported by the International Science \& Technology Cooperation Program of China (No. 2014DFA30900), National Natural Science Foundation of
China (No. 81673519) and National Major New Drug Creation Project of China (No. 2020ZX09201010).

\section{Disclosure}

The authors report no conflicts of interest in this work.

\section{References}

1. Domino EF, Chodoff P, Corssen G. Pharmacologic effects of CI-581, a new dissociative anesthetic, in man. Clin Pharmacol Ther. 1965;6:279-291. doi:10.1002/cpt196563279

2. Mion G, Villevieille T. Ketamine pharmacology: an update (pharmacodynamics and molecular aspects, recent findings). CNS Neurosci Ther. 2013;19(6):370-380. doi:10.1111/cns.12099

3. Salloum NC, Fava M, Freeman MP, et al. Efficacy of intravenous ketamine treatment in anxious versus nonanxious unipolar treatment-resistant depression. Depress Anxiety. 2019;36(3):235-243. doi:10.1002/da.22875

4. Frey TM, Florin TA, Caruso M, Zhang N, Zhang Y, Mittiga MR. Effect of intranasal ketamine vs fentanyl on pain reduction for extremity injuries in children: the PRIME randomized clinical trial. JAMA Pediatr. 2019;173(2):140-146. doi:10.1001/jamapediatrics

5. Kapur J. Role of NMDA receptors in the pathophysiology and treatment of status epilepticus. Epilepsia Open. 2018;3(Suppl 2):165-168. doi:10.1002/epi4.12270

6. Domino EF. Taming the ketamine tiger. Anesthesiology. 2010;113 (3):678-684. doi:10.1097/ALN.0b013e3181ed09a2

7. Laskowski K, Stirling A, McKay WP, Lim HJ. A systematic review of intravenous ketamine for postoperative analgesia. Can J Anaesth. 2011;58(10):911-923. doi:10.1007/s12630-011-9560-0

8. Bell RF, Dahl JB, Moore RA, Kalso E. Peri-operative ketamine for acute post-operative pain: a quantitative and qualitative systematic review (Cochrane review). Acta Anaesthesiol Scand. 2005;49 (10):1405-1428. doi:10.1111/j.1399-6576.2005.00814.x

9. Peltoniemi MA, Hagelberg NM, Olkkola KT, Saari TI. Ketamine: a review of clinical pharmacokinetics and pharmacodynamics in anesthesia and pain therapy. Clin Pharmacokinet. 2016;55 (9):1059-1077. doi:10.1007/s40262-016-0383-6

10. Sinner B, Graf BM. Ketamine. Handb Exp Pharmacol. 2008;182:313-333. doi:10.1007/978-3-540-74806-9_15

11. Zanos P, Moaddel R, Morris PJ, et al. Ketamine and ketamine metabolite pharmacology: insights into therapeutic mechanisms. Pharmacol Rev. 2018;70(3):621-660. doi:10.1124/pr.116.01519 8 err

12. Himmelseher S, Pfenninger E. [The clinical use of S-(+)-ketamine a determination of its place]. Anasthesiol Intensivmed Notfallmed Schmerzther. 1998;33(12):764-770. doi:10.1055/s-2007-994851

13. Adams HA, Werner C. [From the racemate to the eutomer: (S)-ketamine. Renaissance of a substance?] Anaesthesist. 1997;46 (12):1026-1042. doi:10.1007/s001010050503

14. White PF, Schuttler J, Shafer A, Stanski DR, Horai Y, Trevor AJ. Comparative pharmacology of the ketamine isomers. Studies in volunteers. Br J Anaesth. 1985;57(2):197-203. doi:10.1093/bja/57.2.197

15. Zou L, Tian SY, Quan X, Ye TH. [Psychedelic effects of subanesthetic doses of ketamine]. Zhongguo Yi Xие Ke Xue Yuan Xиe Bao. 2009;31(1):68-72.

16. Bowdle TA, Radant AD, Cowley DS, Kharasch ED, Strassman RJ, Roy-Byrne PP. Psychedelic effects of ketamine in healthy volunteers: relationship to steady-state plasma concentrations. Anesthesiology. 1998;88(1):82-88. doi:10.1097/00000542-1998010 00-00015

17. Pfenninger EG, Durieux ME, Himmelseher S. Cognitive impairment after small-dose ketamine isomers in comparison to equianalgesic racemic ketamine in human volunteers. Anesthesiology. 2002;96 (2):357-366. doi:10.1097/00000542-200202000-00022 
18. Engelhardt W, Stahl K, Marouche A, Hartung E. [Recovery time after (S)-ketamine or ketamine racemate. Recovery time after short anesthesia in volunteers]. Anaesthesist. 1998;47(3):184-192. doi:10. 1007/s001010050546

19. Geisslinger G, Hering W, Thomann P, Knoll R, Kamp HD, Brune K. Pharmacokinetics and pharmacodynamics of ketamine enantiomers in surgical patients using a stereoselective analytical method. Br J Anaesth. 1993;70(6):666-671. doi:10.1093/bja/ 70.6.666

20. Ihmsen H, Geisslinger G, Schuttler J. Stereoselective pharmacokinetics of ketamine: $\mathrm{R}(-)$-ketamine inhibits the elimination of $\mathrm{S}(+)--$ ketamine. Clin Pharmacol Ther. 2001;70(5):431-438. doi:10.1067/ mcp.2001.119722
21. State Food and Drug Administration. Good clinical practice guideline. Available from: http://www.sda.gov.cn/WS01/CL0053/ 24473.html. Accessed August 6, 2003.

22. State Food and Drug Administration. Guidelines for the study of clinical pharmacokinetics of chemical drugs. Available from: http://samr.cfda. gov.cn/WS01/CL1616/83420.html. Accessed March 18, 2005.

23. US Food and Drug Administration. Guidance for industry of statistical approaches to establishing bioequivalence. Available from: https:// www.fda.gov/media/70958/download. Accessed January, 2001.

24. Sigtermans M, Dahan A, Mooren R, et al. S(+)-ketamine effect on experimental pain and cardiac output: a population pharmacokinetic-pharmacodynamic modeling study in healthy volunteers. Anesthesiology. 2009;111(4):892-903. doi:10.1097/ ALN.0b013e3181b437b1

\section{Publish your work in this journal}

Drug Design, Development and Therapy is an international, peerreviewed open-access journal that spans the spectrum of drug design and development through to clinical applications. Clinical outcomes, patient safety, and programs for the development and effective, safe, and sustained use of medicines are a feature of the journal, which has also been accepted for indexing on PubMed Central. The manuscript management system is completely online and includes a very quick and fair peer-review system, which is all easy to use. Visit http://www. dovepress.com/testimonials.php to read real quotes from published authors. 